\title{
Bilateral Molars and Premolars Intrusion Using 2 Miniscrews and Acrylic Plate: A Case Report
}

\section{Amjad Al Taki ${ }^{*}$ and Mazen R Sbeih ${ }^{2}$}

${ }^{1}$ Associate Professor, Private Practice, Department of Orthodontics, Smile Spa

Dental Clinic, Dubai UAE

${ }^{2}$ Assistant Professor Orthodontic Department Al-Quds University, West Bank,

Palestine

*Corresponding Author: Amjad Al Taki, Associate Professor, Private Practice,

Department of Orthodontics, Smile Spa Dental Clinic, Dubai UAE.
Received: July 06, 2021

Published: August 24, 2021

(C) All rights are reserved by Amjad Al Taki

and Mazen R Sbeih.

\begin{abstract}
Introduction: The skeletal anterior open bite may be treated using mini-screws as a complete anchorage is provided for correction of the open bite through the intrusion of the maxillary molars. The case presented herein used mini-screws along with a specially designed acrylic plate.

Case Report: A 13-year-old female patient with a Class 2 div 1 malocclusion, anterior open bite, supra-erupted posterior teeth, and the dual occlusal plane was treated using two mini screws along with an acrylic plate.

Results: The molar intrusion was achieved significantly with a mandibular counterclockwise movement, improving the facial profile and thus reducing the open bite.

Conclusion: The anterior open bite was adequately corrected using mini-screws along with an acrylic plate, without significant side effects.
\end{abstract}

Keywords: Open Bite; Maxillary Molar; Intrusion; Malocclusion

\section{Introduction}

According to the "Glossary of Orthodontic Terms" open bite is defined as a developmental or acquired malocclusion where no vertical overlap exists between maxillary and mandibular anterior or posterior teeth [1]. The term "open bite" was initially given in 1842 by Caravelli.

The open bite may be anterior or posterior. Anterior open bite is a multifactorial entity. The main characteristics are the enhanced height of the lower third of the face and steep mandibular plane owing to the over-eruption of the maxillary posterior teeth $[2,3]$. The treatment of anterior open-bite poses certain challenges in orthodontics. The management included both surgical and non- surgical alternatives. The surgical treatment involves realignment of the maxilla with or without performing mandibular ramus osteotomy along with orthodontic treatment [4]. However, the surgery may involve various risks and high costs, thus alternative clinical procedures have been investigated for the maxillary posterior teeth intrusion. Non-surgical alternatives include the use of aligners, the use of occlusal adjustment appliances, the intrusion of anterior or posterior teeth. The patient's esthetic and functional demands are considered while choosing the desired alternative.

This case report shows the patient with skeletal and dental Class II malocclusion along with an anterior open-bite who was 
treated using two mini screws along with a specialized design of acrylic splint appliance.

\section{Case Report}

A 13-year-old female patient presented to the Orthodontics clinic with the chief complaint of the vertical gap between her front teeth and difficulty in closing the lips at rest. The detailed history revealed the patient's mouth breathing habit.

The photographs of the face demonstrated convex profile, lip incompetence, and long face pattern (Figure 1). The patient had a posterior gummy smile.
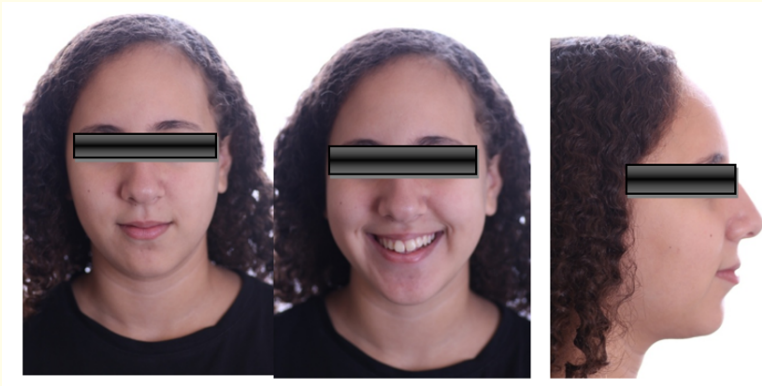

Figure 1: Pre-treatment extraoral photographs.

On intraoral examination, a Class 2 div 1 malocclusion, anterior open bite, supra-erupted posterior teeth (Figure 2), and dual occlusal plane (Figure 2c) were detected. The patient had acceptable oral health. No decay or gingival inflammation was noted.
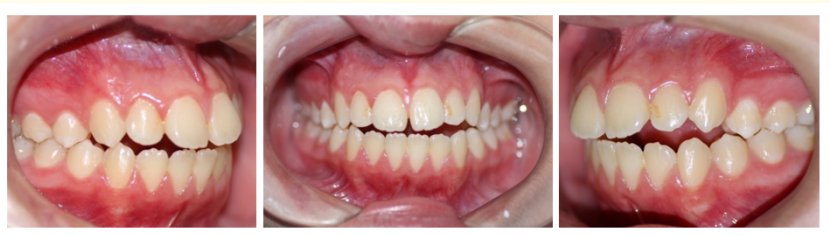

Figure 2: Pre-treatment intra-oral photographs; note the supra-erupted posterior teeth.

Lateral cephalogram analysis revealed a skeletal Class II pattern due to mandibular retroposition (ANB: $6^{\circ}$ ) and vertical growth. Re- garding etiology, poor anterior maxillary growth and an increased posterior maxillary height were determined as the causes of the malocclusion (Figure 3).

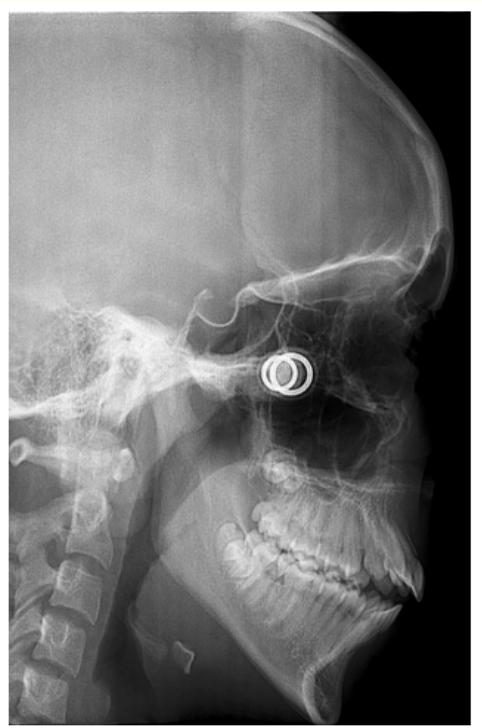

Figure 3: Pre-treatment lateral cephalogram.

\section{Treatment goals}

The treatment was based on the correction of facial, skeletal, dental, and functional components. The facial correction aimed to improve the profile, reduce lip incompetence, and correct the gummy smile. The skeletal correction aimed to reduce the anterior overbite. Based on the dual occlusal plane (Figure 2), treatment was planned on intruding the posterior segment of teeth. This was planned to level the posterior occlusal plane using the anterior plane as reference. The functional correction was performed to improve respiratory function.

\section{Treatment alternatives}

The various treatment alternatives available are:

1. Orthognathic surgery: It mainly consists of performing LeFort I surgery for realignment of the maxilla. It could not be performed in the present case as patient consent was not obtained.

2. Extraction of the four maxillary and mandibular first premolars: Although this would have permitted the correc- 
tion, there is an increased probability of effects on the patient's facial profile, with the vertical dimensional increase.

3. The extrusion of maxillary incisors: This is conventionally achieved using extrusion arch [5]. However, it has the limitation of relapse.

4. The intrusion of upper molars using mini-implants: The molar intrusion is considered the most stable alternative for performing a camouflage treatment. Thus, the placement of two mini-screws on the palate between the first and second molars is proposed, along with an appliance resembling a bite block, cemented into the maxillary molars. Elastomeric chains assist in its activation, from the mini-implants to the appliance. This further helps in the intrusion of the molars without causing unwanted side effects such as inclination.

\section{Treatment progress}

a) Intrusion phase: The upper posterior acrylic cap splint appliance was fabricated using the following components. The acrylic component comprised occlusal coverage, which extended from the first premolars to the second molars on each side. The transpalatal bars consisted of two transpalatal bars (1.1 mm thickness each) to connect both sides and to prevent the posterior teeth from tipping buccally during the intrusion. The buccal hooks were used mesial and distal to the first molars. These hooks extended buccally from the acrylic splint, to serve as a point of attachment during application of the force (Figure 4). The temporary anchorage device (TAD) was also used ( $3 \mathrm{M}^{\mathrm{TM}}$ Unitek $\left.^{\mathrm{TM}} \mathrm{TAD}, 8 \mathrm{~mm}\right)$. Two TADs were screwed in the inter radicular space between the second premolar and first molar region on both sides. The 9 $\mathrm{mm} \mathrm{Ni-Ti}{ }^{\circledR}$ Springs with eyelets were used (Closed-Coil, Ormco) to apply the intrusion force (Figure 5). The treatment duration was 6 months of intrusion.

b) Orthodontic brackets phase: This was performed using $0.014 ", 0.018$ ", and 0.018" × 0.022" NiTi archwires, followed by $0.019 " \times 0.025 "$ Stainless steel archwire. The intrusion was followed by 6 months using orthodontic brackets to level and align both arches $\left(3 \mathrm{M}^{\mathrm{TM}}\right.$ Victory Series ${ }^{\mathrm{TM}}$ Bracket System 0.022 inch) (Figure 6). The periodontist was consulted for Phase I (hygiene and control) and the patient was educated and motivated for maintenance of oral hygiene. The fixed appliance was removed after 6 months.
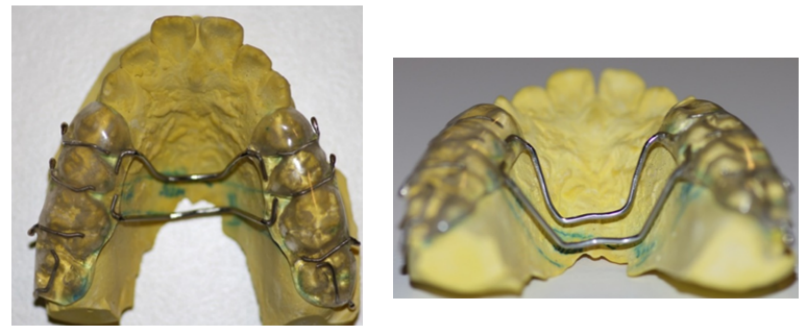

Figure 4: Acrylic splint photographs. Note palatal bars 4 - $5 \mathrm{~mm}$ away from the palate.
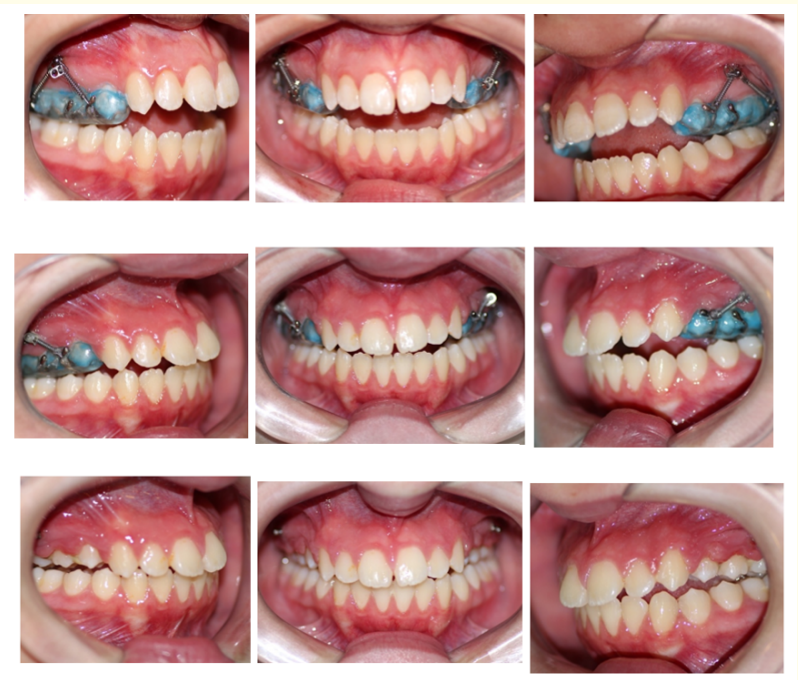

Figure 5: Intrusion phase.

c) Retention phase: The upper and lower bonded retainers were used.

\section{Results}

Post-treatment a proper alignment and acceptable occlusion were achieved. A normal Class 1 molar-to-molar relationship was obtained. The improvement in facial profile was noted and the lip incompetence was corrected (Figure 7). Teeth intercuspation and root parallelism were adequate. 


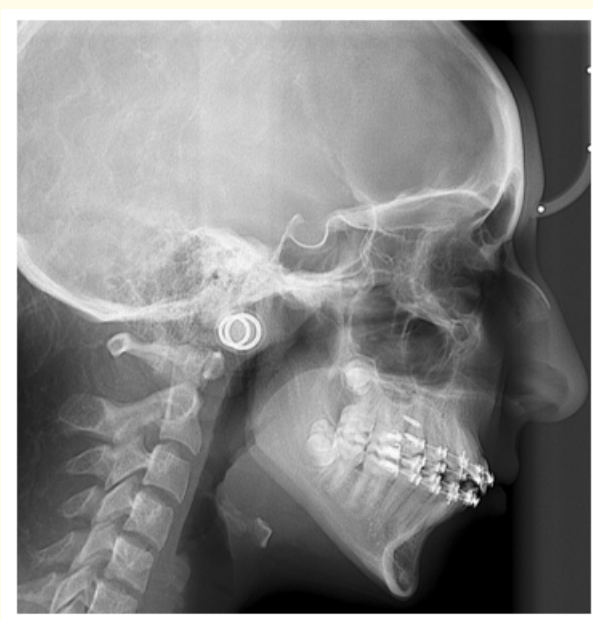

Figure 6: Intraoral photographs and lateral cephalogram during fixed orthodontic phase.
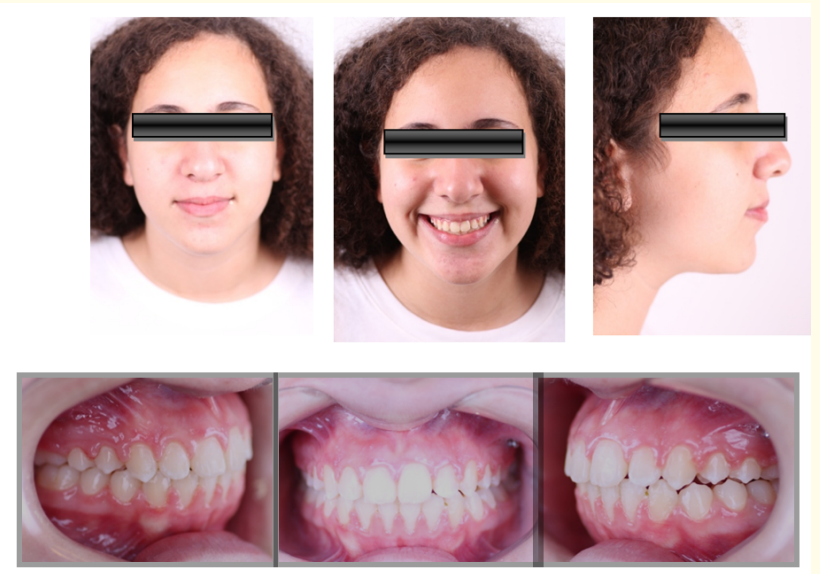

Figure 7: Post-treatment extra-oral and intra-oral photographs.

\section{Discussion}

The characteristics of an anterior open bite are variable. However, it is most commonly characterized by the over-eruption of the maxillary posterior teeth [6]. Thus, the clinicians aim to correct the open bite by the intrusion of over-erupted teeth. Corrective nonsurgical orthodontic treatments are acceptable treatment alterna- tives. Skeletal anchorage using mini-screws has been well-established for the intrusion of teeth that are over-erupted [7]. Several studies have reported significant intrusion of molars for treating anterior open bite using TADs [8]. This is a novel treatment alternative reducing the anterior facial height vertically, advancing the chin, and rotating the mandible counterclockwise. This occurs without any intervention surgically or elongation of incisors. The present case report demonstrated that intrusion of maxillary posterior teeth along with correction of the open bite could be effectively obtained using miniplate anchorage.

The molar intrusion may be utilized for correction of anterior open bite aiming to reduce the height of the lower third of the face. Mini implants and mini plates can be used for molar intrusion as they are associated with minimum limitations such as poor patient compliance [9]. Mini implants have several advantages such as minimal cost, simple procedure, etc. However, it requires adequate treatment planning. In the present case, no extraction was performed.

Posterior intrusion using mini-implants for correction of the anterior open bite is well described by several authors $[10,11]$. The introduction of mini-implants has widened the spectrum of orthodontic treatment modalities. The number of implants that should be placed and their location is decided based on various factors such as several teeth to be intruded, size and root surface area of teeth, and the proper balance of forces. In the present case, one mini-implant was placed on either side buccally between the maxillary second premolar and first molar. The buccal segment was stabilized using a transpalatal arch [TPA]. This was performed to prevent buccal flaring.

Pekhale., et al. [11] in their study discussed the stress pattern on the posterior maxillary segment that was intruded using miniimplant anchorage. Based on their results, they concluded that TPA is mandatory in posterior segmental intrusion to prevent flaring. However, they advocated using three implants (two buccal and one palatal) along with TPA for stability. Nevertheless, using two implants in the present case, desired results were achieved.

\section{Conclusion}

The upper molar intrusion therapy is considered more reliable than the anterior teeth extrusion for the closure of open bite. The two mini-implants when used on the palate combined with a modi- 
fied acrylic plate provided significant control three-dimensionally avoiding any unwanted tipping of the maxillary molars while performing intrusion.

\section{Bibliography}

1. Denny JM., et al. "Anterior open bite and overjet treated with camouflage therapy". American Journal of Orthodontics and Dentofacial Orthopedics 131.5 (2007): 670-678.

2. Buschang PH., et al. "Early treatment of hyperdivergent openbite malocclusions". Seminars in Orthodontics 8.3 (2002): 130140 .

3. Lopez-Gavito G., et al. "Anterior open-bite malocclusion: A longitudinal 10-year postretention evaluation of orthodontically treated patients". American Journal of Orthodontics 87.3 (1985): 175-186.

4. Lawry DM., et al. "A review of the management of anterior open bite malocclusion". The Australasian Orthodontic Journal 11.3 (1990): 147-160.

5. Isaacson RJ and Lindauer SJ. "Closing anterior open bites: The extrusion arch". Seminars in Orthodontics 7.1 (2001): 34-41.

6. Erverdi N., et al. "The use of skeletal anchorage in open bite treatment: A cephalometric evaluation". The Angle Orthodontist 74.3 (2004): 381-390.

7. Daimaruya T., et al. "The influences of molar intrusion on the inferior alveolar neurovascular bundle and root using the skeletal anchorage system in dogs". The Angle Orthodontist 71.1 (2001): 60-70.

8. Sherwood KH., et al. "Closing anterior open bites by intruding molars with titanium miniplate anchorage". American Journal of Orthodontics and Dentofacial Orthopedics 122.6 (2002): 593600 .

9. Xun C., et al. "Microscrew anchorage in skeletal anterior openbite treatment". The Angle Orthodontist 77 (2006): 47-56.

10. Jnaneshwar PR., et al. "Treatment of anterior open bite using mini-implants". International Journal of Orthodontic Rehabilitation's 10 (2019): 92-94.
11. Pekhale N., et al. "Evaluation of stress patterns on maxillary posterior segment when intruded with mini implant anchorage: A three-dimensional finite element study". The APOS Trends in Orthodontics 6 (2016): 18-23.

\section{Volume 5 Issue 9 September 2021}

(C) All rights are reserved by Amjad Al Taki and Mazen R Sbeih. 